\title{
Article \\ Synthetic Jet Actuators with the Same Cross-Sectional Area Orifices-Flow and Acoustic Aspects
}

\author{
Emil Smyk ${ }^{1, *(\mathbb{D}}$, Joanna Wilk ${ }^{2}$ ad and Marek Markowicz $^{2}(\mathbb{D}$ \\ 1 Faculty of Mechanical Engineering, UTP University of Science and Technology, Al. Prof. S. Kaliskiego 7, \\ 85-796 Bydgoszcz, Poland \\ 2 Faculty of Mechanical Engineering, Rzeszów University of Technology, al. Powstańców Warszawy 12, \\ 35-959 Rzeszów, Poland; joanwilk@prz.edu.pl (J.W.); m.markowicz@prz.edu.pl (M.M.) \\ * Correspondence: emil.smyk@utp.edu.pl
}

Citation: Smyk, E.; Wilk, J.;

Markowicz, M. Synthetic Jet

Actuators with the Same

Cross-Sectional Area Orifices-Flow

and Acoustic Aspects. Appl. Sci. 2021,

11, 4600. https://doi.org/10.3390/

app11104600

Academic Editor: Roberto Camussi

Received: 8 April 2021

Accepted: 14 May 2021

Published: 18 May 2021

Publisher's Note: MDPI stays neutral with regard to jurisdictional claims in published maps and institutional affiliations.

Copyright: (c) 2021 by the authors. Licensee MDPI, Basel, Switzerland. This article is an open access article distributed under the terms and conditions of the Creative Commons Attribution (CC BY) license (https:// creativecommons.org/licenses/by/ $4.0 /)$.

\begin{abstract}
In this paper, synthetic jet actuators (SJAs) with three different orifice shapes (circular, square, and slot) with the same cross-section area were investigated. The SJA efficiency and the synthetic jet (SJ) Reynolds number were calculated based on the time-mean reaction force measurement. The momentum velocity was measured with hot-wire anemometry and additionally, the sound pressure level (SPL) was measured. The efficiency was equal maximally to $5.3 \%$ for each orifice shape, but the square orifice characterized the higher Reynolds number. The compared centerline (axial) velocities and the radial velocity profile at a distance of $112 \mathrm{~mm}$ were similar for each orifice type. The SPL measurement results were surprisingly constant in relation to each other. The square orifice generates the lowest SPL, approximately $2.8 \mathrm{~dB}$ lower than the circular orifice, and approximately $4.2 \mathrm{~dB}$ lower than the slot orifice, at each investigated real power. Finally, the differences to other papers and limitations of the approach to comparing orifices presented in the present paper were indicated.
\end{abstract}

Keywords: ZNMF; noise; orifice; efficiency

\section{Introduction}

The synthetic jet actuator (SJA) is a simple device consisting of only three parts: cavity, the orifice or nozzle (one or many), and the movable or deformable element. The modifications of shape, the number, or the dimension of cavity or orifice may significantly change the parameters of the generated synthetic jet (SJ). A specific case may limit the ability to change these parameters or oblige their specific shape or type [1-3]. The use of more than one movable or deformable element is also possible and beneficial [3,4], but this can cause a significant increase in the actuator size especially in the case of mechanics and acoustic actuators, and limit their applicability. The modification of SJA cavity dimensions [5] and shape [6] both have an impact on the produced SJ, but the modification of the orifice is much easier and more important in terms of SJA application and design than the other two possibilities. The modification and increasing of the SJA parameters are important, especially for their application. The SJA can be used for enhanced heat transfer [7-9], mixing [10-12], or broadly defined active flow control [13-15].

Chaudhari et al. [16] investigated how the orifice shape impacts the heat transfer from an impinging SJ. Authors investigate SJAs with a slot orifice with different aspect ratios and hydraulic diameters, and SJAs with different orifice shapes. The comparison of Nusselt numbers for different orifice types shows that the square orifice gives a maximum heat transfer coefficient for the axial distance $x / d>5$, where $x$ is the orifice-wall distance and $d$ is the hydraulic diameter of the orifice. The slot (rectangular) orifice was better for smaller axial distances, $x / d<5$. The circular orifice generates the lowest heat transfer coefficient. This phenomenon was explained in [17], where the topology of SJ generated by SJAs with the slot and the circular orifice were compared. The impact of orifice shape on the heat 
transfer coefficient was also investigated by Mangate and Chaudhari [18] for oval and diamond shapes. However, these shapes of the orifice did not give better results than the rectangular and square orifices. The other authors investigated not only the impact of shape on SJ parameters but also the number of orifices [19-21].

The change of orifice dimension is also significant. The aspect ratio [16] in the case of the rectangular orifice and the diameter [22] in the case of the circular orifice are as important as its shape. Jani et al. [22] showed that there exists an optimal diameter for which the velocity of SJ is maximal, the method of determination of which was presented by Kordík and Trávníček [23]. However, Jani et al. [22] also investigated orifices with the walls inclined at different angles. In other words, they changed the orifices into nozzles with different tapering. The parameters of SJs, the Reynolds number and the mass flow rate, were dependent on the nozzle angle, but the effect of orifice geometry in synthetic jets was not clear.

Kordík and Trávníček [24] investigated SJAs with five different types of nozzle. They designed nozzles by adding other plates with profiled nozzles and measured the time-mean reaction force generated by each SJA. The results were related to the reference nozzle (the sharp-edged nozzle- essentially a circular orifice). The actuators with all tested nozzle types generated higher time-mean reaction forces than the actuator with the sharp-edged nozzle. This means that for these nozzles, the SJ velocity, the Reynolds number [25], and the energetic efficiency [26] were also higher. The replacement of the orifice with the nozzle may also be more practical; for example, for noise reduction chevron nozzles are used [27,28], although the effect can also be obtained for chevron orifices [29].

The orifice with oscillating cross-section area [30,31], the virtual orifice [32], or using the confinement effect $[33,34]$ are the other methods of changing the SJ parameters by the change of the orifice. However, the authors of this paper decided to choose the simpler and more basic method of orifice modification. The circular, square, and slot orifices were tested and the parameters of SJ and SJA were compared. As a comparative criterion, the crosssection area of the orifice was chosen, and the orifice length was equal to a characteristic dimension for a suitable shape of the orifice.

The main scope of the present paper was determining the impact of the orifice crosssection shape on the SJ parameters and checking whether the cross-sectional area can be a comparative criterion for the orifice. The search for a parameter that can be used as a base parameter is especially important during research because it allows excluding its influence on the obtained results. In our opinion, the hydraulic diameter (the most used) is not the best benchmark for SJA. The hydraulic diameter should be used for flows with low dynamics. However, Persoons and O'Donovan [35] provided a correlation between the pressure loss coefficient for steady flow through the short orifice and pressure loss coefficient for the SJ, and the use of hydraulic orifices is justified but we will try to show that it is the criterion of the same orifice cross-section area which is more suitable. Additionally, the noises generated by actuators with different orifice shapes were measured.

\section{Materials and Methods}

In the paper, three different orifice shapes were investigated-circular, square, and slot (the most often studied shapes of orifices). The cross-section area of orifices was similar, and the geometric parameters were presented in Table 1. Although it is customary to compare orifices with the same hydraulics diameters $[16,18,36]$, the authors of this paper believe that it is the cross-sectional area and not the hydraulic diameter that may have a decisive influence on the flow parameters. The $S J$ is a quick-changing phenomenon and the viscous forces between the fluid and the orifice walls may be less important than flow damping due to a changes in cross-section. The orifice height was equal to a diameter in the case of the circular orifice, as a side length in the case of the square orifice, and as a width in the case of slot orifice. Most often, the orifice height is less than the orifice diameter, and this case can be treated as borderline between the short and long orifices. 
Table 1. Parameters of orifices for different shapes.

\begin{tabular}{|c|c|c|c|c|c|}
\hline $\begin{array}{c}\text { Orifice } \\
\text { Type }\end{array}$ & $\begin{array}{c}\text { Characteristic } \\
\text { Dimension } \\
\text { of Orifice } \\
\text { [mm] }\end{array}$ & $\begin{array}{c}\text { Hydraulics } \\
\text { Diameter, } d_{h} \\
{[\mathrm{~mm}]}\end{array}$ & $\begin{array}{c}\text { Equivalent } \\
\text { Diameter, } d^{\prime} \\
{[\mathrm{mm}]}\end{array}$ & $\begin{array}{c}\text { Orifice } \\
\text { Height, } t \\
\text { [mm] }\end{array}$ & $\begin{array}{l}\text { The } \\
\text { Cross-Section } \\
\text { Area of the } \\
\text { Orifice, } \mathrm{A}\left[\mathrm{mm}^{2}\right]\end{array}$ \\
\hline circular & $d=22.4$ & 22.4 & 22.4 & 22.4 & 394 \\
\hline square & $a=b=20$ & 20 & 22.57 & 20 & 400 \\
\hline slot & $\begin{array}{l}a=10 \\
b=40\end{array}$ & 16 & 22.57 & 10 & 400 \\
\hline
\end{tabular}

The orifices were printed from PETG (polyethylene terephthalate glycol-modified) using 3D technology. The thickness of the wall of the orifice was $2 \mathrm{~mm}$. The actuator body was made of PMMA and loudspeaker STX M.18.200.8.MCX was used. The diameter of the actuator cavity was $150 \mathrm{~mm}$, and the height was $20 \mathrm{~mm}$.

The SJA was supplied with a sinusoidal signal generator by a Rigol GD4162 and amplified by an AUNA CD-708 amplifier. The current and voltage drops were measured with Keithley 2701 instruments (6.5 digits, 22-bits) with a 7706 all-in-one I/O module. The current was measured as a voltage drop on a reference resistor $(1 \Omega, \pm 0.01 \%)$.

The velocity was measured with a hot-wire anemometer (HWA). The two-wire constant temperature anemometer (CTA) probe connected to the ATU 08 bridge was used. The first wire used for velocity measurements was calibrated in the range of $0.3-49 \mathrm{~m} / \mathrm{s}$ and the second wire was used for the temperature measurements. The CTA probe was mounted on a 3D manipulator with $\pm 0.02 \mathrm{~mm}$ positioning accuracy.

The sampling rate was 2000 samples per one SJA operation period. The velocity was calculated based on 100 cycles for each single measurement. For example, for a SJA fed with a frequency $40 \mathrm{~Hz}$ the sampling frequency was $80,000 \mathrm{~S} / \mathrm{s}$ and the total number of samples was $8,000,000$.

The energetic efficiency, Reynolds number, and stroke length were calculated using the method proposed by Gil [25,37] and Gil and Smyk [26]. For this reason, the time-mean reaction force of SJA was measured with precision balance RADWAG WTC2000. The resolution of this device was $0.01 \mathrm{~g}$ and the range was $2000 \mathrm{~g}$.

The SPL measurements were made with a Testo $816-1$ equipped with a $1 / 2$ " microphone. The equipment was compiled with the requirements of the IEC 61672-1 Class 2 standard. Its measuring range was $35-100 \mathrm{~dB}(\mathrm{~A})$ in a frequency of $20-8000 \mathrm{~Hz}$. The back-ground SPL of the environment was confirmed to be at least $10 \mathrm{~dB}$ lower than the SPL generated by the SJA. Type A frequency weighting was applied to the SPL measurements (SPL (A)). The SPL measurements performed according to the ISO 3746:2010 [38].

A Honeywell HPB200W2DA-B barometer was used for the atmospheric pressure measurement. The accuracy of measurement was $\pm 40 \mathrm{~Pa}$. The air temperature during measurements was in the range of $19-21.5^{\circ} \mathrm{C}$.

LabVIEW software with the NI-USB-6211 card was used to all devices control. The photo of some part of the measurement stand and its scheme was presented in Figure 1 and the accuracy of measured values is presented in Table 2. 
(a)

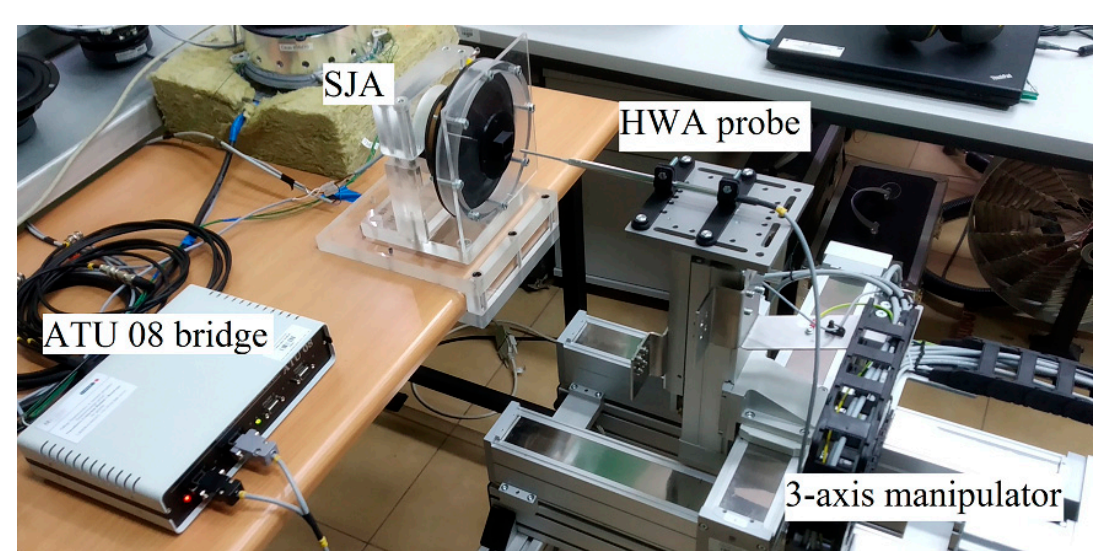

(b)

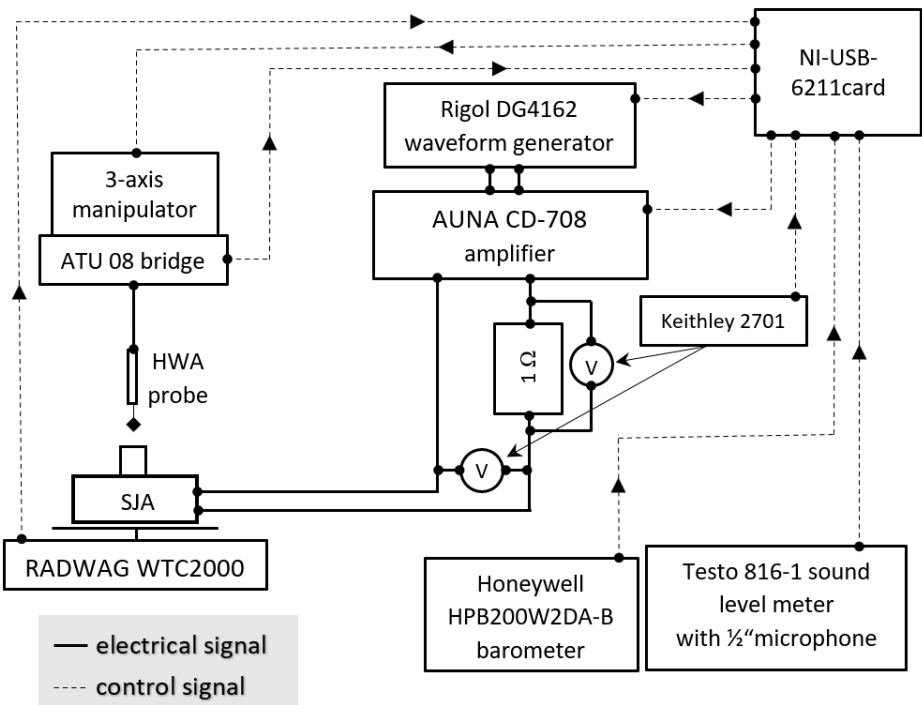

Figure 1. Photo of some parts of the measurements stand (a) and its scheme (b).

Table 2. Measurement uncertainties.

\begin{tabular}{ccc}
\hline Name & Relative Accuracy & Absolute Accuracy \\
\hline Power, $P$ & $\pm 2 \%$ & \\
Force, $F$ & & $\pm 1 \mathrm{mN}$ \\
Velocity, $u$ (calibration accuracy) & $\pm 2 \%(2.6-49 \mathrm{~m} / \mathrm{s})$ & $\pm 0.1 \mathrm{~m} / \mathrm{s}(<2.6 \mathrm{~m} / \mathrm{s})$ \\
Efficiency, $\eta$ & $\pm 0.2 \%$ \\
SPL & $\pm 1.4 \mathrm{~dB}$ \\
\hline
\end{tabular}

\section{Data Reduction}

The energetic efficiency, Reynolds number, and stroke length were calculated using the time-mean reaction force as $[25,26,37]$ :

$$
\begin{aligned}
& \eta=\frac{1}{2 P} \sqrt{\frac{F^{3}}{A \cdot \rho}} \\
& \operatorname{Re}=\frac{l}{v} \sqrt{\frac{F}{A \cdot \rho}}
\end{aligned}
$$

and

$$
L=\frac{1}{2 f} \sqrt{\frac{F}{A \cdot \rho}}
$$


where $f$ is the frequency of loudspeaker diaphragm oscillation $(\mathrm{Hz}), F$ is the time-mean reaction force $(\mathrm{N}), A$ is the cross-section area of the orifice $\left(\mathrm{m}^{2}\right), \rho$ is the air density calculated from the ideal gas formula $\left(\mathrm{kg} / \mathrm{m}^{3}\right), l$ is characteristic dimension $(\mathrm{m}), v$ is the kinematic viscosity of fluid $\left(\mathrm{mm}^{2} / \mathrm{s}\right)$, and the real power is calculated as:

$$
P=E I \cdot \cos \varphi
$$

where $E$ is effective voltage $(\mathrm{V}), I$ is effective current $(A)$ and $\cos \varphi$ is the power factor.

However, the authors want to compare the orifices with the same cross-section area and not with the same hydraulic diameter. For this reason, it was decided to use the equivalent diameter as the characteristic dimension (see Table 1):

$$
d^{\prime}=\sqrt{4 \frac{A}{\pi}}
$$

The velocity measurements were made as momentum velocity measurements for one hundred cycles. The data were then averaged to one representative cycle. The momentum velocity was calculated from [39] as:

$$
U_{\mathrm{rms}}=\sqrt{\frac{1}{T} \int\left(u_{c}^{2}\right) \mathrm{d} \tau}
$$

where $T$ is a period of oscillation, $T=1 / f(\mathrm{~s}), u_{c}$ is the instantaneous velocity at the orifice axis $(\mathrm{m} / \mathrm{s}), \tau$ is a time $(\mathrm{s})$.

During the velocity measurements the parameter $r$ was recognized as the distance between the geometric center of the orifice cross-section area and the wall (Figure 2). As a parameter, $x$ was recognized as the distance from the orifice end to the measurement point.

(a)
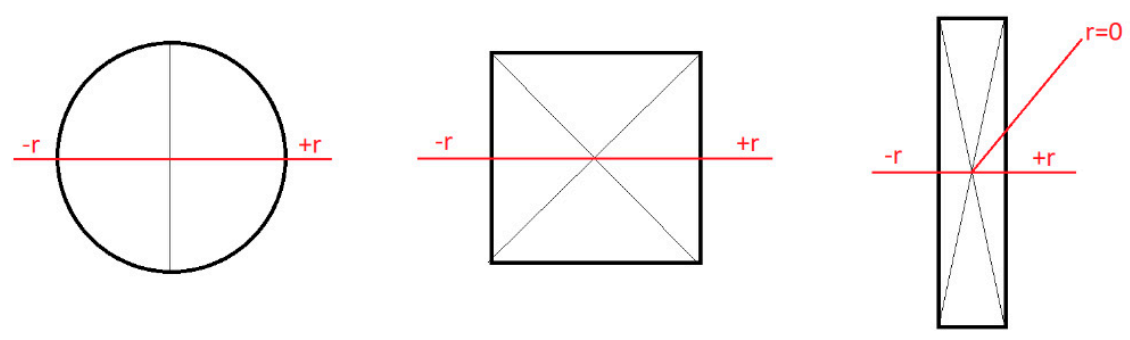

(b)

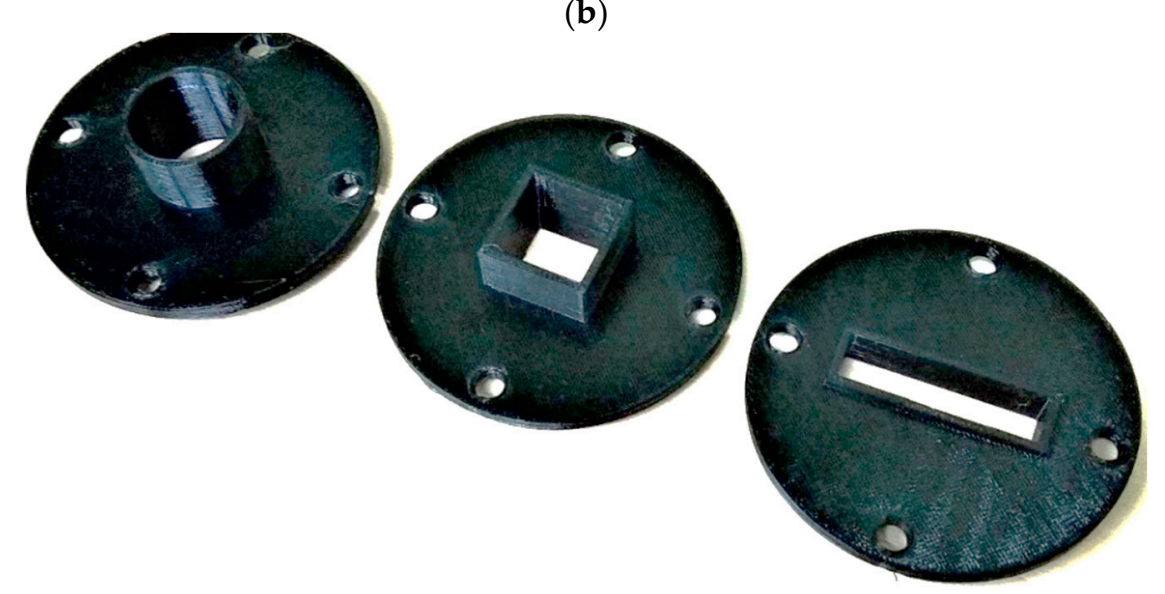

Figure 2. The location of parameter of $r$ on the orifice cross-section area (a) and the photo of printed orifices $(\mathbf{b})$. 


\section{Results and Discussion}

\subsection{Time-Mean Reaction Force Measurements}

In Figure 3a, the Reynolds number for different orifice types as a function of frequency are shown. The course of the charts is very similar and it is only for $f>50 \mathrm{~Hz}$ that the value of the Reynolds number begins to differ significantly. The Reynolds numbers of SJAs with circular and square orifices are the same. Based on Reynolds numbers, the characteristic frequency of SJs can be designed as $f=44 \mathrm{~Hz}$ for the circular and the square orifice at Reynolds numbers equal to 13,174 and 13,219 respectively, and $f=54 \mathrm{~Hz}$ at Reynolds number 13213 for the slot orifice. It can be assumed that the Reynolds number calculated for the equivalent diameter is independent of the orifice shape at the resonant frequency. This is confirmed by the dependence presented in Figure $3 b$.

(a)

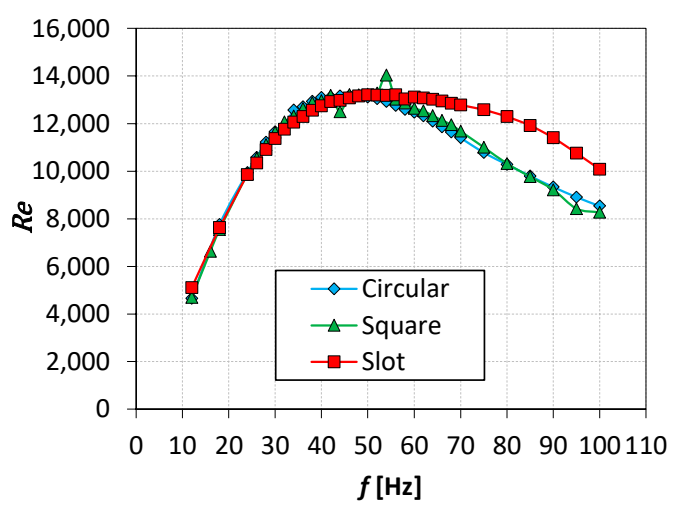

(b)

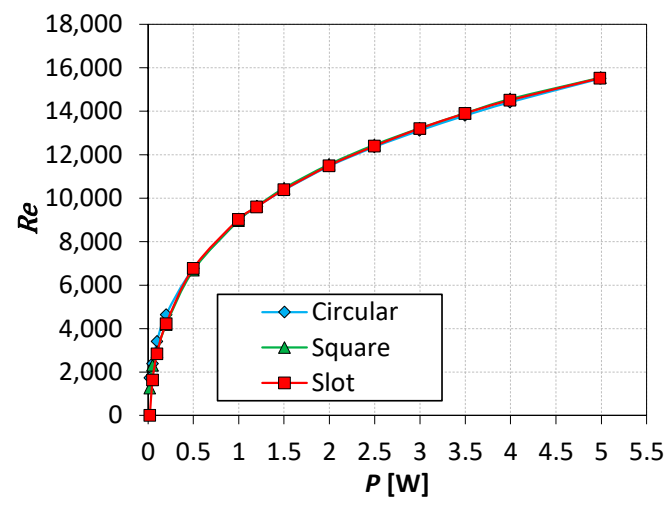

Figure 3. Reynolds number of $\mathrm{SJ}$ as a function of frequency at real power $P=3 \mathrm{~W}$ (a) and as a function of real power at a resonant frequency $(\mathbf{b})$.

In Figure 4 the dimensionless stroke length was presented. This parameter is used as a formation criterion of SJ. It must be noted, that in this case the equivalent diameter was used [40], the hydraulic diameter [41], or another parameter e.g., slot width [5,42]. The formation criterion was fulfilled in the whole measuring range. This issue is described in more detail in [34]. Milanovic and Zaman [43] defined the formation criterion as $L / d>0.4$. In this case, the diameter $d$ can be understood as hydraulic diameter $d_{h}$. Because $d^{\prime} \geq d_{h}$ then $L / d \geq L / d^{\prime} \geq 0.4$. Thus, the criterion is fulfilled. The dimensionless stroke length for the slot orifice is smaller than for other orifices. Generally, the higher the power, the higher the difference, and at the $P=5 \mathrm{~W}$ the dimensionless stroke length for the slot orifice is about $18 \%$ smaller than for the circular or rectangular orifice.

(a)

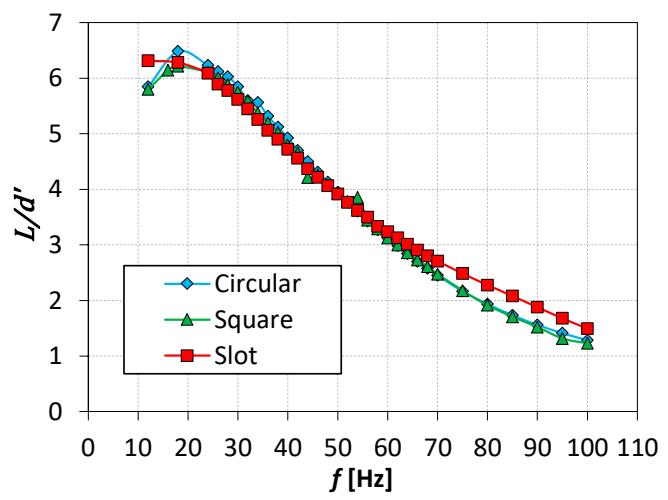

(b)

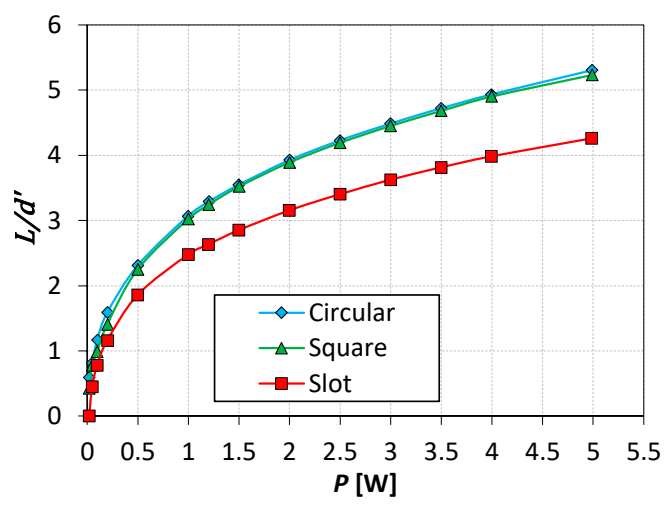

Figure 4. Dimensionless stroke length of $\mathrm{SJ}$ as a function of frequency at real power $P=3 \mathrm{~W}(\mathbf{a})$ and as a function of real power at a resonant frequency $(\mathbf{b})$. 
In Figure 5 the energetic efficiency of an SJA as a function of frequency at real power $P=3 \mathrm{~W}$ (Figure $5 \mathrm{a}$ ) and as a function of real power at a resonant frequency (Figure $5 \mathrm{~b}$ ) were presented. The resonant frequency of the SJA designated based on efficiency is the same as in the case of the Reynolds number. The maximum efficiency was the same for each orifice and was equal to $5.3 \%$. The increase of real power does not increase the energetic efficiency of the SJA (Figure $5 b$ ). That this course of efficiency charts as a function of real power is typical and it can be observed in many papers for different actuator types $[8,26,29,34]$. The electrical efficiency function of the SJA was independent of the orifice shape.

(a)

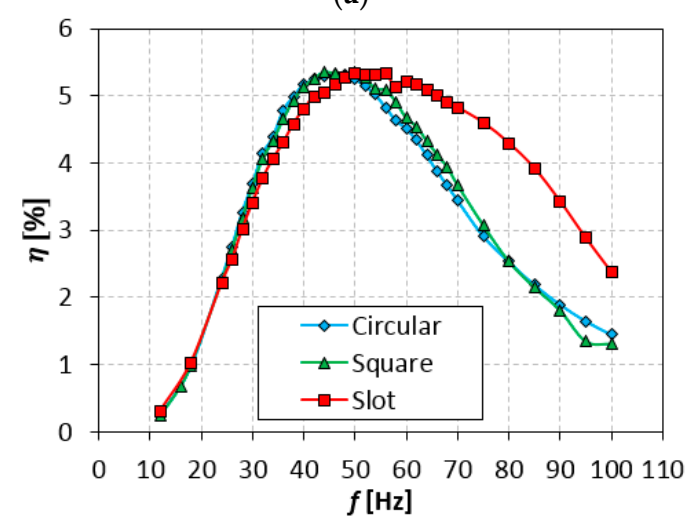

(b)

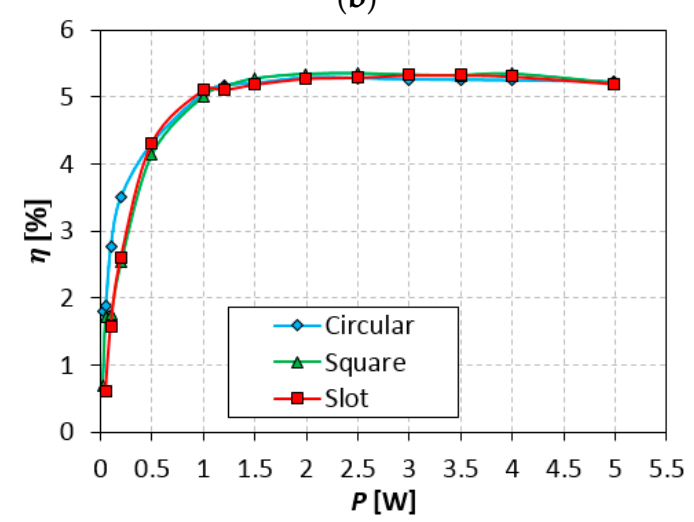

Figure 5. The energetic efficiency of SJA as a function of frequency at real power $P=3 \mathrm{~W}(\mathbf{a})$ and as a function of real power at a resonant frequency $(\mathbf{b})$.

The Reynolds number (Figure 3), the dimensionless stroke length (Figure 4), and the efficiency (Figure 5) are similar and independent of the orifice shape for frequency $f<$ 60. The dimensionless stroke length as a function of real power (Figure $4 \mathrm{~b}$ ) for the slot orifice also differs from other cases. This may be due to a fact that the Equations (1)-(3) have been checked and confirmed only for axisymmetric, circular orifices. However, these differences are not particularly significant because the SJA operates mainly at resonant frequencies. However, this is an area that should be additionally investigated with the use of velocity measurement.

\subsection{Impact of the Hydraulic Diameter on Results}

The choosing of equivalent diameter as a characteristic dimension had an impact on the presented results. The Reynolds number is directly proportional to the characteristic dimensions and a dimensionless stroke length is inversely proportional to the square of the characteristic diameter. The time-mean reaction force method of the energetic efficiency calculation is independent of the characteristic diameter. The percentage changes of Reynolds number and dimensionless stroke length when considering the hydraulic diameter are shown in Table 3.

Table 3. Change of parameters for the hydraulic diameter.

\begin{tabular}{ccc}
\hline Orifice Type & Reynolds Number & Dimensionless Stroke Length \\
\hline circular & $0 \%$ & $0 \%$ \\
square & $-11.39 \%$ & $+25.44 \%$ \\
slot & $-29.11 \%$ & $+96 \%$ \\
\hline
\end{tabular}

The choice of the equivalent diameter instead of the hydraulic diameter causes an increase of Reynolds number in the case of the square and slot orifice and a decrease of dimensionless stroke length. The dimensionless stroke length is used generally only for the formation criterion validation. However, Gil [25] showed that the formation criterion is met if the SJA generates the time-mean reaction force higher than zero and this criterion 
can be used by the reaction force measurement. In the case of the calculation of stroke length based on the velocity measurements, the difference between dimensionless stroke length calculated for the hydraulic diameter and for the equivalent diameter will be not so large as values presented in Table 3 (the stroke length will be independent of the chosen characteristic diameter), and the formation criterion formed by Holman et al. [44] or Milanovic and Zaman [43] can be easily modified to account for the equivalent diameter.

The changes in the values of the Reynolds number may seem more controversial. The Reynolds number is the ratio between the internal and viscous force and is used for the flow classification and in the scaling of different-sized flows. This dimensionless number was used initially only for flows in pipes and for this reason, it is customary to use the hydraulic diameter for its calculation. However, it is not the rule and, for example, Smith and Glezer [45] applied the width of the slot orifice. Additionally, in the case of SJ, the diameter of the orifice (hydraulic or equivalent) is equal to or higher than the orifice height. For this reason, the viscous forces between the orifice walls and the fluid are less important than the shape of the orifice (viscous forces in the fluid). For example, Miró et al. [17] showed that the SJ generated by an actuator with a circular orifice is less turbulent than the SJ generated by an actuator with a slot orifice. There are more differences in the topology of the SJ generated by different orifice shapes [5].

The SJA had a similar energetic efficiency at the resonant frequency and the real power (Figure $5 b$ ) and it can suggest that the flow conditions were also similar. It must be noted that the calculations of SJ and SJA parameters based on the time-mean force reaction measurements are independent of the orifice shape [26], in contrast to the velocity calculation method.

Taking all the above facts into account, one would expect the Reynolds number for all orifice types to be similar as well. For the hydraulic diameter, that is not true. However, in the case of the equivalent diameter, this is. For this reason, we believe that the equivalent diameter is better suited to calculate parameters when comparing actuators with orifices of different shapes than the hydraulic diameter.

\subsection{The Centerline Velocity Measurements}

The centerline exit $(x=r=0 \mathrm{~mm}$ ) momentum velocity as a function of the frequency and the real power of SJA is presented in Figure 6. The course of the velocity charts (Figure 6a) is similar to the Reynolds number charts (Figure 3). This confirms the correctness and compatibility of the methods used because these values are directly proportional to each other-Figure 3 has been drawn from a time-mean force measurement and Figure 6 from hot-wire velocity measurement. Additionally, note that the velocity measured at the center of the cross-section area is representative and can be used to calculate the mean velocity value $[40,46]$.

(a)

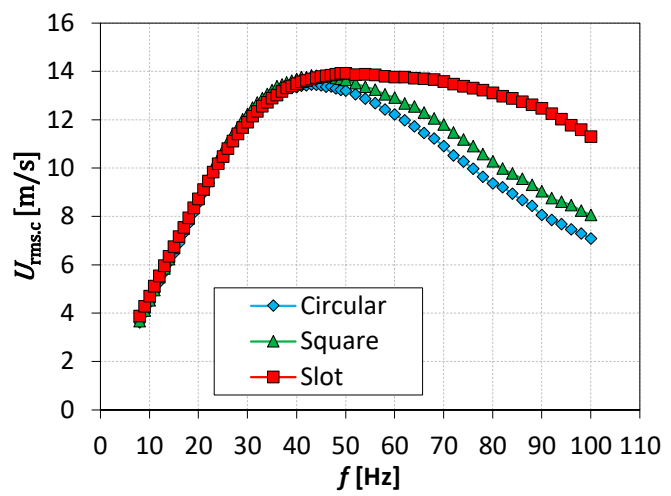

(b)

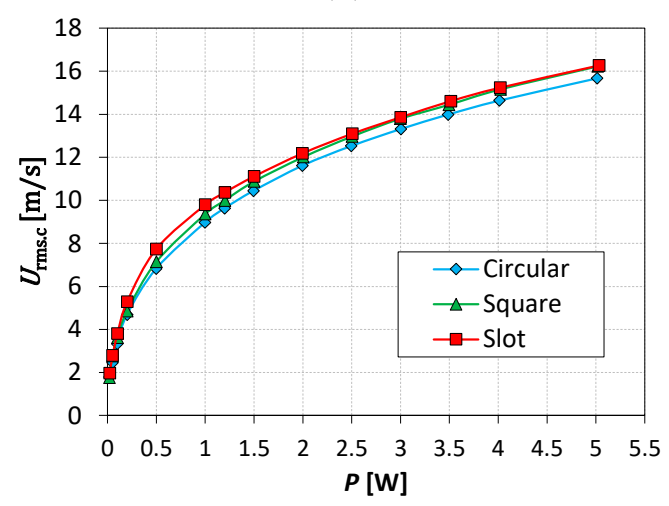

Figure 6. The centerline momentum velocity of SJ as a function of frequency at real power $P=3 \mathrm{~W}(\mathbf{a})$ and as a function of real power at a characteristic frequency (b) at $x=0 \mathrm{~mm}$, and $r=0 \mathrm{~mm}$. 
The centerline momentum velocity of SJ as a function of real power was similar for each type of orifice. However, the velocity for the slot orifice was higher than others, especially at small real power, $P<2 \mathrm{~W}$. The centerline momentum velocity for slot orifice was even $12.5 \%$ higher at $P=0.1 \mathrm{~W}$ than the velocity for circular orifice. At $P>2 \mathrm{~W}$ difference between velocity for slot and square orifice was circle $2 \%$ and it is the value equal to measurement uncertainties. The minimal difference between the velocity for slot and circular orifice was $3.6 \%$.

\subsection{Axial and Radial Velocity Profiles}

Figure 7 presents the axial profile of $S \mathrm{~J}$ centerline $(r=0 \mathrm{~mm})$ momentum velocity at a characteristic frequency and $P=3 \mathrm{~W}$. The profiles for all orifice types were similar.

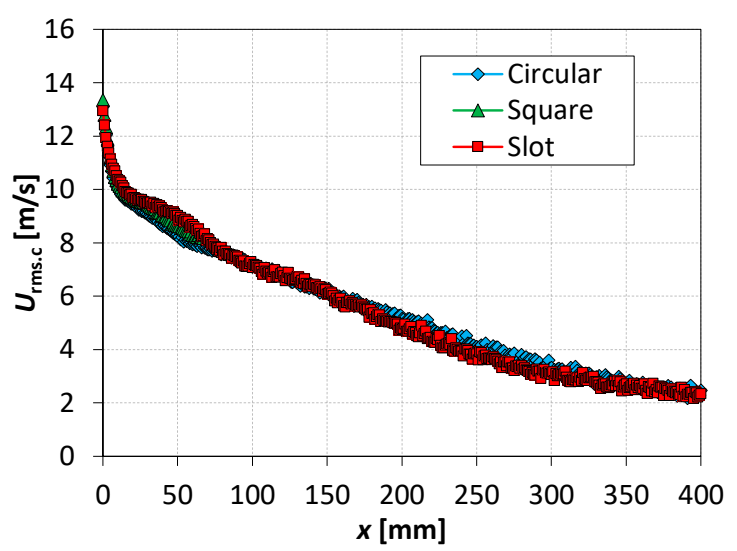

Figure 7. The centerline, axial profile of SJ centerline momentum velocity of $\mathrm{SJ}$ at a characteristic frequency, $P=3 \mathrm{~W}, r=0 \mathrm{~mm}$.

In the range $10<x<50$, the highest values were obtained for the slot orifice and the lowest for circular orifice, but in the range $150<x<400$ the highest values were obtained for square orifice and the lowest for slot orifice. The maximum difference between the individual values was $30 \%$. This chart of axial distribution of centerline momentum velocity is typical $[39,47,48]$.

Figure 8 presents the radial velocity profile at a characteristic frequency, the real power $P=3 \mathrm{~W}$, and $x / d^{\prime}=5$. The velocity radial profile at $x / d^{\prime}=5$ was similar for each type of orifice. The highest value was obtained for the square orifice and the velocity value was about $4 \%$ higher in this case than for the circular and slot orifices. This distance $x / d^{\prime}=5$ (about $112 \mathrm{~mm}$ ) was indicated as the most advantageous in heat in heat exchange by Gil et al. [39]. Bhapkar et al. [49] obtained the highest average Nusselt number for $x / d^{\prime}=3$ (about $36 \mathrm{~mm}$ ), and in [50] this distance was specified as $x / d_{h}=10$. Nevertheless, the degree of similarity of the profiles is still surprising.

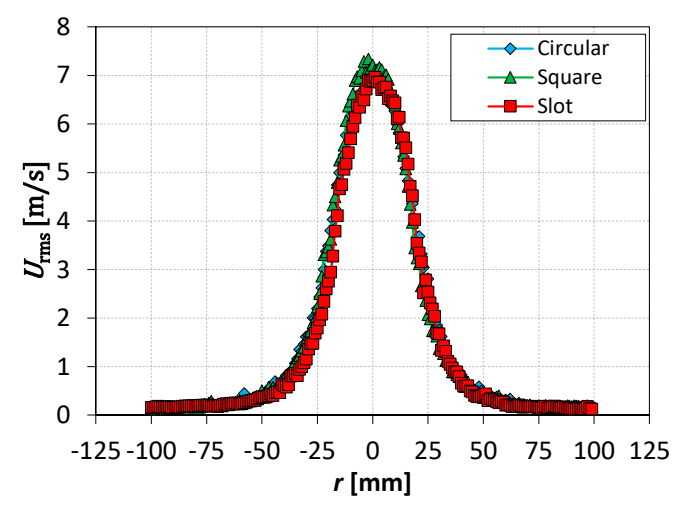

Figure 8. The radial profile of momentum velocity of SJ at a characteristic frequency, $P=3 \mathrm{~W}, x / d^{\prime}=5$. 


\subsection{SPL Measurements}

Figure 9 presents the SPL for different SJA real powers at a characteristic frequency. The SPL was measured at $P=0.02 ; 0.05 ; 0.1 ; 0.2 ; 0.5 ; 1 ; 1.2 ; 1.5 ; 2 ; 2.5 ; 3 ; 3.5 ; 4 ; 5 \mathrm{~W}$. However, the SPL at $P<1 \mathrm{~W}$ was lower than $46 \mathrm{~dB}$ for all orifice type. According to ISO 3746:2010 [38], the measured SPL should be $10 \mathrm{~dB}$ higher than the noise background level, which was $36 \mathrm{~dB}$. With that in mind, only the measurements at $P>1.5 \mathrm{~W}$ can be considered compliant with the standard. However, the authors decided to extend the presented range of measurement data because it shows the same trend.

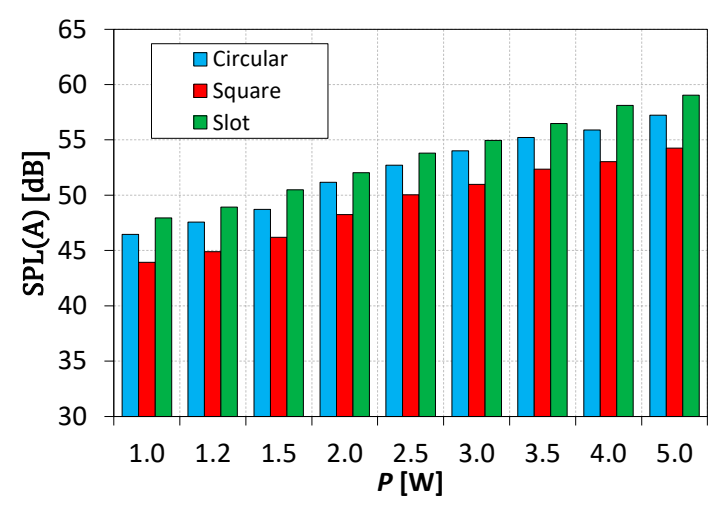

Figure 9. The SPL for different SJA real power at a characteristic frequency.

The SPL was the lowest for the square orifice at all SJA powers. It is important that difference of the SPL for different orifice shapes was relatively constant. The SPL for the square orifice was about $5.7 \pm 0.3 \%(2.8 \pm 0.2 \mathrm{~dB})$ lower than the SPL for the circular orifice and about $7.9 \pm 0.7 \%(4.2 \pm 0.5 \mathrm{~dB})$ lower than the SPL for the slot orifice. The SPL for the slot orifice was higher about $2.7 \pm 0.8 \%(1.4 \pm 0.4 \mathrm{~dB})$ than the SPL for the circular orifice.

The SPL for different orifice types can also be compared for different frequencies [51]. For this reason, the SPL as a function of SJA frequency at $P=3 \mathrm{~W}$ is presented in Figure 10. Similarly, at the resonant frequency the lowest SPL was observed for the square orifice. This relationship was maintained in the entire studied frequency range. The slot orifice generated higher SPL than the circle orifice across the entire frequency range, except for frequencies close to $100 \mathrm{~Hz}$.

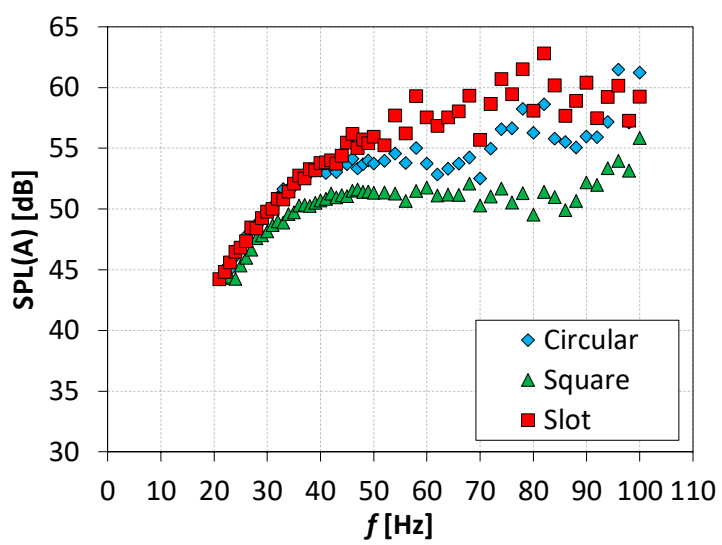

Figure 10. The SPL as a function of SJA frequency at $P=3 \mathrm{~W}$.

Bhapkar et al. [51] studied the SPL generated by SJAs with circular, elliptical, square, and elliptical orifices. The results presented in their work were not so clear-cut. The SPL generated by an actuator with a different orifice shape was strongly dependent on the frequency and on the basis of measurements presented by Bhapkar et al. In [51] it is impossible to clearly assess which orifice generated less noise. In the case of the research presented in this paper, however, it is unequivocally possible. 
Additionally, Bhapkar et al. [51] showed that the higher the orifice, the greater the SPL. According to these studies, the shorter the orifice (in our case slot), the lower the noise level generated. This relationship is not maintained in the case of the presented measurements. It must therefore be concluded that it is the shape of the orifice that is decisive regarding the SPL and not the orifice.

\subsection{Differences from Other Studies}

The equivalent diameter is used also in other papers [51]. However, there are a few differences between this article and the most common approach to SJ investigation. Firstly, as a characteristic diameter of SJA, the equivalent diameter was used. Similar to diameter in the case of the circular orifice or the width in the case of slot orifice, it is a dimension parameter. The dimensionless parameter, which is not mentioned in the paper but could be used as a characteristic parameter, is the aspect ratio. However, the aspect ratio for circular and square orifices is equal to $A R=1$, and in the case of the slot orifice is $A R=0.25$. As such, this parameter, and the others mentioned, also prevents the tested nozzles from being considered similar.

Secondly, the orifice height is different for each orifice and is equal to the diameter/side/width in the case of the circular/square/slot orifice. Normally the orifice height is the same for each actuator. It is also a characteristic parameter and affects the parameters of the generated SJ, as for example the Reynolds number, the SJ velocity and the SJA efficiency [47,52], or the SPL [51]. However, these dependencies were not found during this research. This is probably due to the fact that the orifice was short-not higher than the characteristic dimension of the orifice shape.

The different shape of the orifice makes the topology of generated SJ significantly different $[17,53,54]$. For this reason, depending on the application, the selected nozzle may perform better or worse. For example, the square and rectangular nozzle are more favorable in cooling applications [16] or in some applications of active flow control [13].

Despite these three fundamental differences, which seem to preclude comparison of these orifices, the obtained results were surprisingly similar. However, keep in mind that these orifices have the same cross-section area and the ratio of the basic design dimension to the orifice height is an equal one. The use of equivalent diameter allowed for the unification of the results and made the results independent of the orifice shape. This can allow better investigation into how other actuator dimensions affect the SJ parameters or how the SJ topology affects, for example, heat exchange. This idea could also be applied to the measurements performed and published, as it fits in with the geometric parameters used in articles. Of course, the presented data do not include the impact of the SJ topology, which has a significant impact on the application of SJA, for example, in the heat transfer [16-18,36].

The consistency of results in the case of the SPL measurements is also worth emphasizing. However, this stability may not be maintained for a larger range of real power, as in [29]. These results are also difficult to compare to others because of the differences that have already been mentioned and the small number of articles dealing with the study of noise generated by the SJA. Performing the tests in accordance with the standard [38] will enable the comparison of results in the future.

\section{Conclusions}

In the paper, SJAs with three different orifices were investigated. The circular, square, and slot orifices had the same cross-section area, and the orifice height was equal to the characteristic size for a given type of orifice, respectively the diameter, the side, and the width.

Although the orifices do not meet the basic criteria of similarity as the same hydraulic diameter or the aspect ratio, the basic characteristics of the SJ were similar for each type of orifice. Among the most important should be mentioned: the Reynolds number and the centerline momentum velocity at the characteristic velocity, and the energetic efficiency in a function of the real power. The similarity concerns both the course of the graphs and 
the obtained values. The differences caused by considering the equivalent diameter to calculate the Reynolds number were also discussed.

The SPL was measured for each type of orifice at different real power. In the entire studied range, the lowest noise was generated by the actuator with the square orifice, and then by the actuator with the circular orifice. The greatest noise was generated by the actuator with the slot orifice, even though the slot orifice had the smallest height and SPL is positively correlated with height [51]. We have thus shown that the shape of the nozzle is more important in terms of the generated noise than the orifice height.

In the end, the differences in the selection method of the orifice parameters in this paper and others were discussed. Due to the similarity of the results this method of the parameters selection seems good for initial orifice selection. It can be the basis for further differentiation and determining how changing geometric parameters affects the specified values when comparing orifices with different shapes.

Author Contributions: Conceptualization, E.S. and J.W.; Methodology, E.S., M.M. and J.W.; Software, Validation, Formal Analysis, Investigation, M.M. and J.W.; Resources, Data Curation, WritingOriginal Draft Preparation, E.S.; Writing—Review \& Editing, E.S., M.M. and J.W.; Visualization, E.S.; Supervision, E.S. and J.W. All authors have read and agreed to the published version of the manuscript.

Funding: This work was supported by the National Center for Research and Development, Poland. Grant No.: LIDER/6/0024/L-10/18/NCBR/2019.

Institutional Review Board Statement: Not applicable.

Informed Consent Statement: Not applicable.

Data Availability Statement: Some or all data generated or used during the study are available from the corresponding author by request.

Conflicts of Interest: The authors declare no conflict of interest.

\section{References}

1. Gil, P. Bluff body drag control using synthetic jet. J. Appl. Fluid Mech. 2019, 12, 293-302. [CrossRef]

2. Liu, Z.; Luo, Z.; Liu, Q.; Zhou, Y. Modulation of driving signals in flow control over an airfoil with synthetic jet. Chin. J. Aeronaut. 2020, 33, 3138-3148. [CrossRef]

3. Smyk, E. Numerical simulation of axisymmetric valve operation for different outer cone angle. EPJ Web Conf. 2017, 143, 02112. [CrossRef]

4. Smyk, E. Interference in axisymmetric synthetic jet actuator. EPJ Web Conf. 2017, 143, 02111. [CrossRef]

5. Hong, M.H.; Cheng, S.Y.; Zhong, S. Effect of geometric parameters on synthetic jet: A review. Phys. Fluids $2020,32,031301$. [CrossRef]

6. Ziadé, P.; Feero, M.A.; Sullivan, P.E. A numerical study on the influence of cavity shape on synthetic jet performance. Int. J. Heat Fluid Flow 2018, 74, 187-197. [CrossRef]

7. Gil, P. Performance of special type heat sink with an integrated synthetic jet actuator. E3S Web Conf. 2019, 100, 00017. [CrossRef]

8. Smyk, E.; Gil, P.; Gałek, R.; Przeszłowski, Ł. Acoustic and Flow Aspects of Novel Synthetic Jet Actuator. Actuators 2020, $9,100$. [CrossRef]

9. Ahmad, M.; Qayoum, A. Investigation of impingement of double orifice synthetic jet for heat and fluid flow characteristics in quiescent flow. Pertan. J. Sci. Technol. 2019, 27, 1181-1206.

10. Xia, Q.; Zhong, S. Enhancement of inline mixing with lateral synthetic jet pairs at low Reynolds numbers: The effect of fluid viscosity. Flow Meas. Instrum. 2017, 53, 308-316. [CrossRef]

11. Wang, P.; Shen, C.-B. Characteristics of mixing enhancement achieved using a pulsed plasma synthetic jet in a supersonic flow. J. Zhejiang Univ. Sci. A 2019, 20, 701-713. [CrossRef]

12. Xia, Q.; Zhong, S. Enhancement of laminar flow mixing using a pair of staggered lateral synthetic jets. Sens. Actuators A Phys. 2014, 207, 75-83. [CrossRef]

13. Yadav, K.R.; Paul, A.R.; Hegde, N.; Jain, A. A comparison of circular and slotted synthetic jets for flow control in a twin air-intake. Def. Sci. J. 2020, 70, 113-121. [CrossRef]

14. Hao, Z.; Liu, G.; Ren, W.; Wang, Y.; Bie, H. Research on the Characteristics of Bluff Body Wake Field Induced by Synthetic Jet with PANS Model. J. Appl. Fluid Mech. 2021, 14, 1053-1063. [CrossRef]

15. Wang, G.; Chu, W.; Zhang, H.; Guo, Z. Effect of Active Flow Control of Endwall Synthetic Jet on the Performance of a Transonic Axial Compressor. J. Appl. Fluid Mech. 2021, 14, 963-977. [CrossRef] 
16. Chaudhari, M.; Puranik, B.; Agrawal, A. Effect of orifice shape in synthetic jet based impingement cooling. Exp. Therm. Fluid Sci. 2010, 34, 246-256. [CrossRef]

17. Miró, A.; Soria, M.; Cajas, J.C.; Rodríguez, I.; Moulinec, C. Flow topology and heat transfer analysis of slotted and axisymmetric synthetic impinging jets. Int. J. Therm. Sci. 2021, 164. [CrossRef]

18. Mangate, L.D.; Chaudhari, M.B. Heat transfer and acoustic study of impinging synthetic jet using diamond and oval shape orifice. Int. J. Therm. Sci. 2015, 89, 100-109. [CrossRef]

19. Greco, C.S.; Castrillo, G.; Crispo, C.M.; Astarita, T.; Cardone, G. Investigation of impinging single and twin circular synthetic jets flow field. Exp. Therm. Fluid Sci. 2016, 74, 354-367. [CrossRef]

20. Qayoum, A.; Malik, A. Influence of the Excitation Frequency and Orifice Geometry on the Fluid Flow and Heat Transfer Characteristics of Synthetic Jet Actuators. Fluid Dyn. 2019, 54, 575-589. [CrossRef]

21. Chiatto, M.; Capuano, F.; de Luca, L. Numerical and experimental characterization of a double-orifice synthetic jet actuator. Meccanica 2018, 53, 2883-2896. [CrossRef]

22. Jain, M.; Puranik, B.; Agrawal, A. A numerical investigation of effects of cavity and orifice parameters on the characteristics of a synthetic jet flow. Sens. Actuators A Phys. 2011, 165, 351-366. [CrossRef]

23. Kordík, J.; Trávníček, Z. Optimal diameter of nozzles of synthetic jet actuators based on electrodynamic transducers. Exp. Therm. Fluid Sci. 2017, 86, 281-294. [CrossRef]

24. Kordík, J.; Trávníček, Z. Novel nozzle shapes for synthetic jet actuators intended to enhance jet momentum flux. Actuators 2018, 7, 53. [CrossRef]

25. Gil, P. Synthetic jet Reynolds number based on reaction force measurement. J. Fluids Struct. 2018, 81, 466-478. [CrossRef]

26. Gil, P.; Smyk, E. Synthetic jet actuator efficiency based on the reaction force measurement. Sens. Actuators A Phys. 2019, 295, 405-413. [CrossRef]

27. Crispo, C.M.; Greco, C.S.; Cardone, G. Flow field features of chevron impinging synthetic jets at short nozzle-to-plate distance. Exp. Therm. Fluid Sci. 2019, 106, 202-214. [CrossRef]

28. Li, X. Experimental Investigation of Jet Flow Fields with Chevron Nozzles. IOP Conf. Ser. Mater. Sci. Eng. 2020, 782. [CrossRef]

29. Smyk, E.; Markowicz, M. Acoustic and flow aspects of synthetic jet actuators with chevron orifices. Appl. Sci. 2021, 11, 652. [CrossRef]

30. Trávnícek, Z.; Broucková, Z. Characterization of Impingement Heat/Mass Transfer to the Synthetic Jet Generated by a Biomimetic Actuator. J. Heat Transf. 2019, 141, 042203. [CrossRef]

31. Travnicek, Z.; Antosova, Z. Impingement heat transfer to the synthetic jet issuing from a nozzle with an oscillating cross section. Int. J. Therm. Sci. 2020, 153, 106349. [CrossRef]

32. Embury, M.C.; Solovitz, S.A. Impingement Cooling Using a Virtual Orifice Synthetic Jet. In Proceedings of the 19th IEEE Intersociety Conference on Thermal and Thermomechanical Phenomena in Electronic Systems (ITherm), Orlando, FL, USA, 21-23 July 2020; pp. 435-441.

33. Bhapkar, U.S.; Srivastava, A.; Agrawal, A. Proper cavity shape can mitigate confinement effect in synthetic jet impingement cooling. Exp. Therm. Fluid Sci. 2015, 68, 392-401. [CrossRef]

34. Smyk, E.; Przeszłowski, Ł.; Strzelczyk, P.M. Impact of the confinement plate on the synthetic jet. AIP Adv. 2020, 10, 105204. [CrossRef]

35. Persoons, T.; O’Donovan, T.S.; Donovan, T.S.O.; Persoons, T.; Donovan, T.S.O. A pressure-based estimate of synthetic jet velocity. Phys. Fluids 2007, 19, 2-5. [CrossRef]

36. Mangate, L.; Yadav, H.; Agrawal, A.; Chaudhari, M. Experimental investigation on thermal and flow characteristics of synthetic jet with multiple-orifice of different shapes. Int. J. Therm. Sci. 2019, 140, 344-357. [CrossRef]

37. Gil, P. Corrigendum to "Synthetic jet Reynolds number based on reaction force measurement" [J. Fluids Struct. 81 (2018) 466-478]. J. Fluids Struct. 2021, 101, 103211. [CrossRef]

38. International Organization for Standardization (ISO). Acoustics-Determination of Sound Power Levels and Sound Energy Levels of Noise Sources Using Sound Pressure-Survey Method Using an Enveloping Measurement Surface over a Reflecting Plane (ISO 3746:2010); ISO: Geneva, Switzerland, 2010; p. 48.

39. Gil, P.; Wilk, J.; Smusz, R.; Gałek, R. Centerline heat transfer coefficient distributions of synthetic jets impingement cooling. Int. J. Heat Mass Transf. 2020, 160, 120147. [CrossRef]

40. Kordík, J.; Trávníček, Z.; Timchenko, V.; Ismail, N.A. The predominant effect of stroke length on velocity profiles at the exit of axisymmetric synthetic jet actuators. Int. J. Heat Fluid Flow 2017, 66, 197-208. [CrossRef]

41. Kumar, A.; Saha, A.K.; Panigrahi, P.K.; Karn, A. On the flow physics and vortex behavior of rectangular orifice synthetic jets. Exp. Therm. Fluid Sci. 2019, 103, 163-181. [CrossRef]

42. Krishnan, G.; Mohseni, K. An Experimental and Analytical Investigation of Rectangular Synthetic Jets. J. Fluids Eng. 2009, 131, 121101. [CrossRef]

43. Milanovic, I.M.; Zaman, K.B.M.Q. Synthetic Jets in Cross-Flow. AIAA J. 2003, 45, 929-940. [CrossRef]

44. Holman, R.; Utturkar, Y.; Mittal, R.; Smith, B.L.; Cattafesta, L. Formation criterion for synthetic jets. AIAA J. 2005, 43, 2110-2116. [CrossRef]

45. Smith, B.L.; Glezer, A. The formation and evolution of synthetic jets. Phys. Fluids 1998, 10, 2281-2297. [CrossRef] 
46. Peszynski, K.; Tesař, V. Algebraic model of turbulent flow in ducts of rectangular cross-section with rounded corners. Flow Meas. Instrum. 2020, 75. [CrossRef]

47. Gil, P.; Strzelczyk, P. Performance and efficiency of loudspeaker driven synthetic jet actuator. Exp. Therm. Fluid Sci. 2016, 76, 163-174. [CrossRef]

48. Chaudhari, M.; Verma, G.; Puranik, B.; Agrawal, A. Frequency response of a synthetic jet cavity. Exp. Therm. Fluid Sci. 2009, 33, 439-448. [CrossRef]

49. Chaudhari, M.; Puranik, B.; Agrawal, A. Multiple orifice synthetic jet for improvement in impingement heat transfer. Int. J. Heat Mass Transf. 2011, 54, 2056-2065. [CrossRef]

50. He, X.; Lustbader, J.A.; Arik, M.; Sharma, R. Heat transfer characteristics of impinging steady and synthetic jets over vertical flat surface. Int. J. Heat Mass Transf. 2015, 80, 825-834. [CrossRef]

51. Bhapkar, U.S.; Srivastava, A.; Agrawal, A. Acoustic and heat transfer characteristics of an impinging elliptical synthetic jet generated by acoustic actuator. Int. J. Heat Mass Transf. 2014, 79, 12-23. [CrossRef]

52. Smyk, E.; Wawrzyniak, S.; Peszyński, K. Synthetic jet actuator with two opposite diaphragms. Mech. Mech. Eng. 2020, 24, 17-25. [CrossRef]

53. Zong, H.; Kotsonis, M. Effect of slotted exit orifice on performance of plasma synthetic jet actuator. Exp. Fluids 2017, 58, 1-17. [CrossRef]

54. Gupta, J.; Satish, S.S.G.; Saha, A.K. Vortex formation in a low aspect ratio synthetic jet. J. Flow Vis. Image Process. 2020, $27,117-141$. [CrossRef] 